\title{
La masculinidad, la feminidad y la novela negra*
}

\author{
Nattie GoLUBOV \\ Universidad Nacional Autónoma de México
}

En este trabajo analizaré cómo la crisis de determinados valores y supuestos de la civilización (masculina) ha afectado a la novela negra, género literario que por definición es masculino y que explícitamente excluye a la mujer como lectora. Me interesa señalar que uno de los personajes de este género, Spenser, de Robert B. Parker, se ha convertido en un detective inverosímil en tanto que por definición se pretendía que el detective fuera "a common man". ${ }^{1}$ La crisis de la representación de la masculinidad ha abierto la posibilidad de que mujeres como V. I. Warshawski y Kinsey Millhone sean detectives verosímiles a pesar de que han adoptado características y comportamientos que tradicionalmente han sido considerados masculinos. Como todos los géneros literarios populares, éste ha evolucionado en relación con transformaciones sociales específicas. No me detendré en el análisis detallado de los textos porque sólo deseo mostrar lo importante que es, desde el punto de vista de una lectora hipotética, que cuando menos dos escritoras hayan logrado expropiarles a los escritores una literatura que, como los westerns, está explícitamente dirigida a hombres porque hace uso de representaciones y fantasías producidas para el consumidor masculino.

Esto lo notamos, por ejemplo, en cómo está representada la mujer en los texos y en la exaltación que se hace del protagonista masculino que a pesar de ser "común" posee cualidades excepcionales. Haré una lectura a contracorriente de la novela negra para mostrar su androcentrismo característico que tanto éxito ha obtenido, como lo constatan las múltiples películas, comics y series de televisión que han utilizado la fórmula

\footnotetext{
- Este trabajo es la reelaboración de una ponencia presentada en la mesa redonda "La imagen de la mujer en la novela policiaca", que se llevó a cabo en julio de 1990 en la Facultad de Filosofia y Letras, UNAM. Quisiera dar las gracias a Charlotte Broad por haberme invitado a participar en el coloquio ¿Quién se robó el centenario de Agatha Christie? Agradezco a Julia Constantino su lectura crítica de este trabajo.

' Raymond CHANDLER, “The Simple Art of Murder", en Pearls Are a Nuisance, p. 189.
} 
básica del género. Parto del supuesto de que las mujeres hemos sido prisioneras de textos, géneros y cánones masculinos.

En su ensayo "The Technology of Gender" Teresa de Lauretis postula lo siguiente: a) la construcción del género es tanto el producto como el proceso de su representación; b) la construcción del género es el producto y el proceso tanto de la representación como de la autorrepresentación; c) la construcción del género tiene lugar hoy en día a través de las muchas tecnologías del género (por ejemplo, el cine) y los discursos institucionales (verbigracia, la teoría) con el poder de controlar el campo de significados sociales, y asi produce, promueve e "implanta" representaciones de género. ${ }^{2}$ La novela negra, tecnología del género popular, mitifica un estereotipo del hombre racional, consciente de sí mismo, de su lugar y deber en el mundo, capaz de redefinir su historia y proyectar su futuro. El detective es resultado de un proceso de mitificación,

[...] un proceso de simbolización inconsciente, como identificación del objeto con una suma de finalidades no siempre racionalizables, como proyección en la imagen de tendencias, aspiraciones y temores, emergidos particularmente en un individuo, en una comunidad, en todo un periodo histórico. ${ }^{3}$

Me parece indiscutible el hecho de que si el receptor de una obra literaria es mujer, su experiencia de lectura es significativamente diferente a la de un hombre. Sabemos que hay múltiples lecturas de un texto, ya que lo actualizamos por medio de la lectura. En el caso de la novela negra, todo lector se identifica con el detective por medio de la narración en primera persona, pero la identificación de una mujer con el héroe resulta probiemática, y gran parte de los críticos de esta literatura suponen que hombres y mujeres construimos el sentido de los textos de manera semejante, como podemos constatar con comentarios como los que siguen:

La novela policiaca debe expresar las experiencias del lector, al mismo tiempo que ofrece cierto derivativo a sus aspiraciones 0 a sus emociones reprimidas. ${ }^{4}$

2 Teresa de LAURETIS, "The Technology of Gender", en Technologies of Gender, pp. 1-30.

${ }^{3}$ Umberto Eco, "El mito de Supermán", en Apocalípticos e integrados, p. 249.

4 Thomas NARCEJAC, Una máquina de leer: la novela policíaca, p. 103. 
Cierto es que, por el lado del lector, la novela policiaca puede aparecer como una especie de exorcismo. El criminal es un elemento de la sociedad que se ha puesto a vivir, como el cáncer, de una manera independiente y sin control. El criminal es siempre un "introvertido", un individuo crispado sobre su propio yo, un "poseído". Por tanto, no sólo es necesario perseguirlo, sino además demostrar que el orden sigue siendo el orden, que la realidad sigue siendo la realidad y que el crimen es una ilusión vencida. Pero el acto que consiste en destruir la ilusión mediante una explicación progresiva es precisamente el de toda iniciación [...] Y el momento solemne en el que el enigma se explica en presencia de todos los personajes de la novela se parece enteramente al de un bautizo de la verdad. ${ }^{5}$

De aquí se desprenden varias preguntas: ¿Las experiencias del detective son iguales a las de una lectora? ¿Sus deseos son los mismos? ¿Reprimen las mismas emociones? ¿Desde qué perspectiva se miran "el orden", "la realidad" y "la verdad" de las que habla el crítico? Para él, como para el lector, el texto sirve como punto de encuentro entre lo personal y lo universal, el lector es invitado a validar la analogía entre la masculinidad y la humanidad, y siente su afinidad con lo universal, con el ser humano paradigmático, porque es hombre. El lector de una novela negra se identificará con el detective que el mismo Raymond Chandler describió así:

$\mathrm{He}$ is the hero. He is everything. He must be a complete man and a common man and yet an unusual man. He must be, to use a rather weathered phrase, a man of honour, by instinct, by inevitability, without thought of it, and certainly without saying it. He must be the best man in his world and a good enough man for any world. ${ }^{6}$

Consideremos el siguiente comentario que un detective de Chandler hace respecto a la señora Prendergast en "Mandarin's Jade": " "To hell with her', I said angrily. 'I wouldn't trust her with my old socks. I hope she gets raped on the way home' ". ${ }^{7}$ Un hombre que lee este comentario se identifica con el héroe, aunque evidentemente no hace falta que en su experiencia particular tenga la fantasía o el deseo de que una mujer sea violada. No hace falta que la identificación sea plena porque la lectura da cabida a las diferencias que puede tener con respecto al detective, y

${ }^{5}$ Ibid., p. 213. El subrayado es mío.

${ }^{6}$ R. CHANDLER, op.cit., p. 189.

${ }^{7}$ R. CHANDLER, “Mandarin's Jade", en Trouble is my Business, p. 223. 
a las diferencias que tiene con respecto a las mujeres. Pero este comentario afecta a una lectora de distinta manera. Las mujeres aprendemos a pensar (y a leer) como hombres, a identificarnos con el punto de vista masculino y a aceptar su sistema de valores como normal y legítimo. Uno de los ejes de este sistema es la misoginia patente del comentario arriba citado, y una lectora reafirmaría esta violencia que se hace a sí misma como justificada y necesaria.

Ante un comentario como ése, una lectora, como su contraparte masculino, ratificará la analogía entre lo masculino y lo universal. El género literario no permite que una lectora se refugie en su diferencia. Por el contrario, se ve involucrada en un proceso que la vuelve contra sí misma. Solicita su complicidad en la elevación de la diferencia masculina postulada como universal y en la denigración de la diferencia femenina como lo Otro misterioso, impredecible, incoherente, disperso, incontrolable, la alteridad enloquecida y enloquecedora. Así, durante el proceso de lectura la mujer se "masculiniza" si permite que el texto controle su lectura, porque ha sido educada y ha interiorizado los valores y estrategias de lectura y aprehensión androcéntricas. Sin embargo, si desea controlar el texto debe hacer una lectura doble, primero como lo exige el texto (es decir como hombre) y después, o simultáneamente, como mujer. Quizá para una lectora la novela negra no sea un medio para explorar "in fantasy the boundary between the permitted and the forbidden and to experience in a carefully controlled way the possibility of stepping across this boundary", 8 sino una experiencia esquizofrénica, porque tiene que imaginarse hombre al tiempo que se identifica con la mujer que es caracterizada como:

[...] una amenaza para los hombres, como si su sexualidad fuera una trampa que sólo se vuelve inofensiva cuando ellas mismas están total y verdaderamente atrapadas. Y en forma ingenua, ésta esuna evaluación realista de parte del héroe, puesto que con monótona regularidad la chica que le hace sucumbir a sus encantos resulta ser la villana de la obra [...] Lo que el héroe desea es una chica que le ofrezca estímulo sexual, una chica que tenga algo de prostituta; en resumen, una "mala mujer". 9

La reacción de una mujer ante aquellas fantasías masculinas - las preocupaciones inconscientes de una cultura patriarcal expresadas de

8 John G. CAWELT1, Adventure, Mystery and Romance, p. 35.

9 Jerty PALMER, Thrillers. La novela de misterio, p. 59. 
manera aceptable - es bifurcada, ya que, por un lado, ella se identifica con y se proyecta en el detective extraordinario que tiene una fortaleza moral y una fidelidad obstinada que le permiten cumplir con su deber y sobrellevar ciertas pruebas "inhumanas" sin ejercer facultades sobrehumanas. Por el otro, al identificarse con él, es cómplice de la reducción de los personajes femeninos estereotipados que forman parte de los obstáculos que el héroe logra sobrellevar en defensa propia, ya que los detectives convierten "el cuerpo femenino desnudo en una forma de tentación, pero en una tentación que pueden resistir" 10 porque ejercen un control ejemplar sobre sus cuerpos y emociones, necesario para sobrevivir en el mundo urbano corrupto en el que viven. El héroe es todo un hombre mientras logre sobrellevar todas las contingencias imprevistas (morales y físicas) sin que su autoestima y su imagen de sí mismo sufran daños irreparables.

Como señala Catherine Belsey, un texto como éstos cumple la función de la ideología (en tanto que funge como tecnología del género), no sólo en su representación del mundo de sujetos consistentes que son el origen del sentido, del conocimiento y de la acción, sino que también ofrece al lector, como la posición desde la que el texto es más inteligible, la posición de un sujeto como origen tanto de la comprensión como de la acción que se desprende de esa comprensión. ${ }^{11}$ A sí, tanto el mundo re-presentado como la recepción de esta representación enaltecen el valor de la libertad individual consciente en un mundo de individuos sin contradicciones (y por lo tanto inalterable), cuyo consciente es libre en tanto que enfatiza el valor supremo de la libertad individual de una ideología de la "libre empresa" que insiste en la soberanía del sujeto individual y su derecho y capacidad de escoger entre una gran gama de alternativas viables (y minimiza las limitaciones impuestas a la libertad individual). El interés de esta ideología es sobre todo el de suprimir el papel que desempeña el lenguaje en la construcción del sujeto y su propio papel en la interpelación del sujeto, para presentar al individuo como libre, unificado y autónomo.

La novela negra nos habla de la interacción de un individuo (el "yo" de la primera persona) y su sociedad. Las novelas aparecen como transcripciones de una serie de eventos en un mundo palpable, interpelando al lector como sujeto capaz de percibir y juzgar la "veracidad" del texto, la interpretación de un mundo coherente, sin contradicciones, como lo

${ }^{10}$ Ibid., p. 58.

11 Catherine BELSEY, "Constructing the Subject: deconstructing the text", en Feminist Criticism and Social Change, pp. 45-64. 
interpreta el mismo detective-narrador cuya (aparente) autonomía es la fuente y la garantía de la "verdad" de su interpretación. Este modelo de comunicación intersubjetiva, de comprensión compartida de un mundo ficcional que representa al "mundo real", es garantía no sólo de la verosimilitud del texto sino de la existencia del lector como individuo autónomo y conocedor en un mundo de sujetos semejantes a él. Así, la novela negra constituye una práctica ideológica en tanto que se dirige a los lectores como sujetos masculinos, interpelándolos para que libremente acepten su subjetividad y su sujeción. El sentido del texto es la construcción del sujeto, el resultado de un intercambio entre la formación social, el lector y el texto. Como dije con anterioridad, hay múltiples lecturas de un texto, pero algunas interpretaciones son "obvias" dentro y a partir de la ideología dominante donde se ubica el lector, y ciertas posiciones del sujeto son de manera evidente las posiciones desde donde se construyen los significados.

La novela negra se caracteriza, como tantas otras narraciones, por una jerarquía de discursos que establecen la "verdad" de la novela. Como muestra Barthes, la narración gira en torno a la creación de un enigma por la instauración del desorden que sacude y remueve los sistemas de significación convencionales, como lo hace el homicidio, por ejemplo. Pero la narración inevitablemente se encamina a la conclusión que también es un momento de revelación: la disolución del enigma por medio del restablecimiento del orden que existía antes del comienzo de la obra. En el momento de la conclusión todos los enigmas se vuelven plenamente inteligibles para el lector, cuando el motivo del crimen y quien lo cometió salen a la luz pública. Pero a lo largo de la narración se mantiene un alto nivel de inteligibilidad como resultado de la jerarquía de discursos en el texto. La jerarquía funciona por medio de un discurso privilegiado (el del detective y su código de honor) que subordina los demás discursos. Así, el texto ofrece al lector una posición de sabiduría que también es una posición de identificación con la voz narrativa que organiza la realidad literaria.

El texto primero construye un conjunto de supuestos que comparten el lector y el detective-narrador, como por ejemplo, "It had to be a woman. A man couldn't have shot him in just that perfectly relaxed position", ${ }^{12}$ que aseguran la inteligibilidad del texto. El lector es un sujeto que sabe y que es testigo de que las verdades compartidas son "obvias" y no pueden ser de otra manera:

${ }^{12}$ R. CHANDLER, "The Lady in the Lake", en Trouble is my Business, p. 321. 
Common sense always speaks too late. Common sense is the guy that tells you you ought to have had your brake relined last week before you smashed a front end this week. Common sense is the Monday morning quarterback who could have won the ball game if he had been on the team. But he never has. Common sense is the little man in a grey suit who never makes a mistake in addition. But it's always somebody else's money he's adding up. ${ }^{13}$

El discurso del sentido común que goza de posición privilegiada en este género tiene un papel constitutivo importante en mantener la centralidad de la diferencia genérica como eje del poder en la realidad literaria. Plantea que las diferencias son naturales y se fundamenta en un conjunto de significados sociales y de maneras particulares de entender el mundo. Estos significados, que favorecen los intereses de grupos sociales particulares, se fijan y se aceptan comúnmente como verdades obvias acerca del mundo y de los sujetos que lo habitan, y remiten a la experiencia como garantía de la verdad, ya sea la experiencia social colectiva o la de un individuo. La experiencia, como el conocimiento de sentido común que produce, es fija, verdadera, y funciona como guía para la acción. El detective, como ser autónomo dueño de sí, es capaz de transformar el mundo a través de su trabajo. El hecho de que "lo efectivamente ideológico también es, al mismo tiempo, necesariamente utópico" 14 implicaría que una novela negra masculina ejerce poder sobre la lectora por los deseos y fantasías auténticos que propician su "masculinización", ya que al fin y al cabo, y como nos explica Showalter, las mujeres vivimos la realidad cotidiana de los hombres y por lo tanto estamos sometidas a los medios que divulgan y crean estas fantasías que, por ejemplo, aprueban la agresividad siempre y cuando salga intacto el héroe vulnerable, y son transformadas en deseos universales: 15 "With fantasy, however, the conscious mind is there like a watchdog, anxious to put things together with a sense of cause and outcome and to do it in such a way that the wish expressed doesn't come into direct conflict with social values". ${ }^{16}$ Debemos suponer que la novela negra satisface deseos, necesidades, aspiraciones y miedos propios de los lectores en una

${ }^{13}$ R. CHANDLER, Playback, p. 79.

14 Fredric JAMESON, "Conclusion: The Dialectic of Utopia and Ideology", en The Political Unconscious, p. 289.

15 Véase Elaine Showalter, "Feminist Criticism in the Wild arness", en The New Feminist Criticism, pp. 243-270.

16 Rosalind CowARD, "The Story", en Female Desire, p. 200. 
sociedad determinada (puesto que más que fantasías personales son públicas y sociales), que aún hoy existen, están activos y reafirman las actitudes sociales dominantes que confirman el poder masculino y la subordinación femenina.

A continuación revisaré algunas de las características que definen a todos los detectives de la novela negra norteamericana para luego describir al detective contemporáneo Spenser, quien modifica la fórmula en tanto que es un héroe "domesticado" con quien comienza a desmitificarse el detective tradicional.

Para empezar, surge una oposición aparentemente irreparable entre las esferas pública y privada que se basa en principios opuestos de asociación. Ésos, a su vez, parten de la oposición básica hombre/mujer, representada por el status social conflictivo del hombre y de la mujer. La esfera pública, a la que pertenece el detective, abarca toda la vida social aparte de la doméstica, y el héroe se rehúsa a perder la privacía de su hogar ya que es el único espacio en el que efectivamente está a salvo del caos exterior. Un día, por ejemplo, llega Marlowe a su apartamento y echa a la mujer de "a small corrupt body" que encuentra en su cama:

I didn't mind what she called me, what anybody called me. But this was the room I had to live in. It was all I had in the way of a home. In it was everything that was mine, that had any association for me, any past, anything that took the place of a family. ${ }^{17}$

El hogar de Marlowe es aquel definido como un ámbito de privacía y protección, donde el héroe a solas cura sus heridas y reconstituye su fuerza de trabajo gastada durante el día de actividad en la esfera pública que, a su vez, está dominada por criterios universales, impersonales y convencionales relacionados con logros, intereses, derechos de igualdad y de propiedad - criterios aplicables sólo a los hombres. En palabras de Hélène Cixous, las masculinidad o los sistemas de valores masculinos "are structured according to an 'economy of the proper'. Proper-propertyappropriate: signalling an emphasis on self-identity, self-aggrandizement and arrogative dominance". 18

El detective vive en un mundo urbano saturado de un mal que ha comenzado a carcomer los cimientos de la clase media, de la ciudadanía respetable y de las instituciones del orden y de la ley:

\footnotetext{
${ }^{17}$ R. ChANDLER, The Big Sleep, p. 147.

18 Toril Mol, Sexual/Textual Politics, p. 110.
} 
The realist in murder writes of a world in which gangsters can rule nations and almost rule cities, in which hotels and apartment houses and celebrated restaurants are owned by men who make their money out of brothels $[\ldots]$. A world where a judge with a cellar full of bootleg liquor can send a man to jail for having a pint in his pocket, where the mayor of your town may have condoned murder as an instrument of money-making, where no man can walk down a dark street in safety because law and order are things that we talk about but refrain from practising. ${ }^{19}$

El investigador privado voluntariamente supervisa los espacios públicos como un vigilante que protege los símbolos de la masculinidad, resguardando al ser masculino del peligro de la corrupción desenfrenada, del materialismo incontrolable y de las mujeres. Todo esto amenaza su individualidad y él lo resiste con estoicismo. Su búsqueda consiste en extirpar el mal y revelar la hipocresía, superando todas las tentaciones y las intimidaciones que cuestionan su imagen, enfrentándolas únicamente con su indiscutible integridad. Su victoria consiste en su capacidad de salir ileso y entero después de sumergirse en las profundidades de la corrupción. Como el epítome de la masculinidad, es un "instinctive protector of the weak, a defender of the innocent, an avenger of the wronged, the one loyal, honest, truly moral man in a corrupt and ambiguous world", ${ }^{20}$ y su masculinidad es confirmada cuando se compara con la de otros personajes masculinos. La justicia se convierte en una preocupación personal y el conflicto entre la ética del investigador y las reglas del orden social recurre una y otra vez. Esto enfatiza el hecho de que él es un "fracasado" sólo en términos de los ideales dominantes de esa sociedad de consumo desmedido, y su capacidad de vivir fuera de este orden es heroica y resultado de su libertad de elección. Así, el héroe defiende un concepto tradicional de masculinidad ideal y de individualismo exacerbado, mediante el dominio y la constante vigilancia de sí mismo que se subliman en el honor personal y en la virtud heroica.

El deber del héroe es el de combatir todo mal conforme busca la verdad: su meta es descubrir el mal que impregna toda su sociedad, no encubrirlo. Esto sólo puede lograrlo si es un individuo intachable, si se mantiene apegado a su propio código moral. El detective no comparte la moralidad y los valores de la sociedad urbana en la que vive, aunque hace lo posible por salvarla de su proceso de degradación. Es un héroe porque

${ }^{19}$ R. ChANDLER, “The Simple Art of Murder”, en Pearls Are a Nuisance, p. 189.

20 J. C. CAWELTI, op.cit., p. 151. 
logra salvaguardar su integridad, aunque dentro de su mundo nunca es objeto de admiración. Como el detective es un hombre común que sufre derrotas comunes, invariablemente vence al criminal al tiempo que pierde algo: "I felt old and tired and not much use to anybody". ${ }^{21}$ Aunque siempre derrotado, el detective jamás abandona su cometido en la vida, a pesar de que en cada caso se la esté jugando en tanto que depende de que su código moral se mantenga intacto, puesto que es lo único que sustenta la imagen que tiene de sí mismo, es lo único que posee y a partir de él construye su visión del mundo. Paranoico y depresivo, dado que es un individuo que enfrenta persecución física y moral, el detective cree que su aislamiento garantiza la integridad de su ser ya que sólo confía y se necesita a sí mismo. Su meta es la de saber que ha hecho todo lo que estaba en su poder por curar al "sistema" desde una posición marginal. Como nos explica Lukacs:

[...] la consecuencia más profunda es tal vez que la entrega triunfa sobre la soledad egocéntrica; no es la entrega a un ideal proyectado desde nosotros y que rebasa ampliamente nuestro máximo, sino la entrega a algo que es independiente de nosotros y ajeno a nosotros, pero que precisamente por eso es simple y tangiblemente real. Esta entrega termina en aislamiento [...] La ética impone a todo hombre el sentimiento de comunidad, si ya no por otras causas, al menos sin duda por el conocimiento de la utilidad inmediata y calculable del trabajo realizado, por pequeño que éste sea. El autoconocimiento de la pura genialidad en su acción no puede ser sino irracional. Su acción es siempre sobreestimada y subestimada a la vez, precisamente porque no puede ser medida con ningún criterio, ni interno ni externo. ${ }^{22}$

El detective, entonces, crea un código moral propio mejor que aquel de la sociedad que lo rodea, y como es "the best man in his world" debe ponerlo a prueba y comprobárselo una y otra vez, para mantener intacta su integridad. Como nos dice Lukacs:

[...] la profesión burguesa como forma de vida significa ante todo el primado de la ética en la vida; que la vida esté dominada por lo que se repite sistemáticamente, regularmente, por lo que siempre retorna de

${ }^{21}$ R. CHANDLER, "Killer in the Rain", en Trouble is my Business, p. 49.

22 Georg LUKACs, "El espíritu burgués y 'L'art pour l'art' ", en El alma y las formas. Teoria de la novela, p. 102. 
acuerdo con el deber, por lo que se tiene que hacer sin tener en cuenta el placer o el displacer. ${ }^{23}$

Los obstáculos con los que el héroe se enfrenta son las mujeres, el sexo, el poder y el dinero. Su deber es imponer su concepto de justicia y establecer el orden social en sus términos; en ocasiones protege y encubre los crímenes de sus clientes porque les debe su lealtad, comete delitos para cumplir con sus cometidos, mostrando así que las fronteras entre el bien y el mal son flexibles. Sin embargo, los personajes femeninos son siempre portadores del mal, de la corrupción, inmorales en tanto que son fácilmente corrompibles por dinero y poder, y si acaso el héroe llega a involucrarse con alguna mujer no permite que eso interfiera con su trabajo, puesto que su vida existe para éste. El héroe existe siempre en el ámbito de lo público, terreno de inseguridad e incertidumbre donde nada es seguro ni permanente; sin embargo, sus valores garantizan cierta seguridad y permanencia. Necesita ese mundo para comprar en él su valor como hombre.

Jerry Palmer, en Thrillers. La novela de misterio, nos explica que el mundo que presenta la novela de misterio es paranoico, porque la paranoia es precisamente la combinación paradójica entre una seguridad irreal -inequívoca - en uno mismo y una constante vigilancia en contra de las conspiraciones. ${ }^{24}$

El detective, precariamente ubicado en las fronteras entre los espacios público y privado (la corrupción se gesta en los espacios privados), está en posición de salvar a su sociedad porque sospecha de todos: cualquiera puede ser un asesino. La comunidad que lo rodea siempre es una presencia para él, y está íntimamente vinculado con sus normas en tanto que, aun cuando se encuentra solo, está en su función de vigilante que sospecha siempre de todos. Puede desempeñar este papel porque es un lobo solitario que interactúa con los demás pero que nunca pertenece al grupo, mantiene su posición social fronteriza porque sólo así es capaz de cumplir con su deber, de mantenerse situado por encima del mundo y vencerlo. Interviene cuando el orden normal de las cosas ha sido amenazado, pues su función es la de restablecer este orden. Al fin y al cabo, el papel que ha elegido es una posición que la sociedad urbana en la que vive le exige y le ha impuesto. Esto es, dada la creciente tendencia a enfatizar la individualidad, la privacía y la autonomía en una sociedad

23 Ibid., p. 101.

24 J. PALMER, op.cit., p. 145. 
urbana, la cohesión social sólo puede garantizarse por la supresión de la anormalidad, la vigilancia y el control de cualquier acto que sea una desviación de las normas dominantes y que pueda amenazar este orden.

Si la novela de detectives se construye sobre la base de una "ideología de la paranoia", y si el detective está encargado de supervisar los espacios públicos como vigilante de los símbolos de la masculinidad, puede suponerse que la paranoia se intensifica cuando estos símbolos entran en crisis. Me referiré a "Masculino, femenino, neutro" de Josep-Vicent Marques para explicar por qué nace un detective contemporáneo como Spenser, que tiene características que adjudicaríamos al mítico Superman, precisamente en un momento histórico en el que la masculinidad tradicional ha entrado en crisis. Marques parte del hecho de que "lo masculino se acaba" 25 por la irrupción de lo femenino.

"Lo femenino" ha sido todo lo que los hombres querían que fuera, todo lo que no deseaban ser, y dado el cuestionamiento que se ha hecho de los supuestos que sustentaban la naturalidad del binomio masculino/ femenino, se ha abierto el camino para lo neutro, "en el sentido de accesible a unos y otras". ${ }^{26}$ Sin embargo, la reconstrucción de lo neutro es tarea exclusiva de las mujeres, porque a nivel subjetivo el hombre "se defiende $o$ entra en crisis, pero no asume la redefinición de su identidad". ${ }^{27}$ Los hombres cuestionan otros aspectos de la cultura y de su papel en ella, y esto "nos invita a reflexionar sobre el hecho de que la misma reivindicación de lo femenino viene propiciada por algo que es en cierto modo neutro si no un signo de crisis masculina: la crisis de la civilización".28

A riesgo de simplificar las hipótesis de Craig Owens (y del feminis$\mathrm{mo}$ ), diría que el feminismo intenta alterar la estabilidad de la posición de dominio en la que "los sistemas representacionales de Occidente sólo admiten una visión, la del sujeto masculino, o más bien postulan el sujeto de representación como absolutamente centrado, unitario, masculino", 29 como queda representado en la novela negra. Owens explica que entre las prohibiciones de la representación occidental, aquellas que carecen de legitimidad, se encuentran las mujeres. Y como éstas no están represen-

${ }^{25}$ Josep-Vicent MARQUES, "Masculino, femenino, neutro", en El Viejo Topo, extra, 10, p. 7 .

${ }^{26}$ Ibid., p. 14.

${ }^{27}$ Ibid., p. 14.

28 Ibid., p. 14.

${ }^{29}$ Craig OWENS, "El discurso de los otros: las feministas y el posmodernismo", en Hal FOSTER, comp., La posmodernidad, p. 95. 
tadas son sólo una figura de lo irrepresentable, como lo Otro, la naturaleza, la locura, etcétera. La crisis de la modernidad, y por lo tanto de la representación del sujeto masculino, es "la pérdida de la narrativa [que] es equivalente a la pérdida de nuestra capacidad para situarnos históricamente".$^{30}$ Uno de los síntomas de la reciente pérdida de la supremacía masculina y de sus representaciones, por muy insignificante que éste parezca, es el hecho de que algunas escritoras han expropiado a los hombres una de sus tecnologias del género para asumir lo que se consideraría una posición masculina al representarse a sí mismas 0 , en términos de Marques, para restablecerle a la novela negra su contenido neutro. Esto es, la realidad literaria de la novela negra que ha sido exclusivamente masculina ha sufrido una transformación importante e irreversible. Como la verosimilitud es históricamente determinada, y como al menos para las lectoras las detectives recién concebidas son verosímiles, puede suponerse que esta apropiación y necesaria transformación del género literario ha sido posible por esta crisis.

Asimismo, Spenser, el detective de Robert B. Parker, también es resultado de esta crisis. El detective no se ha modificado radicalmente, sino que más bien ha exacerbado aquellas propiedades masculinas tradicionales en un intento por salvaguardarlas. Spenser es tan paternalista que llega al extremo de adoptar al hijo de una pareja divorciada en Early Autumn, se convierte en el protector de una feminista lesbiana en Looking for Rachel Wallace, y se hace cargo de una prostituta en $\mathrm{Ce}$ remony y en Taming a Sea-Horse. Este cuidado de los otros tradicionalmente ha sido considerado como quehacer femenino. La impartición de la justicia, patrimonio de los detectives tradicionales como Marlowe, da lugar a la instrucción de los niños, de las mujeres descarriadas y de los adolescentes mal encaminados. Spenser, ex boxeador profesional, es un hombre que depende de su fuerza física, no bebe nada más que cerveza, prepara platillos complicados (quehacer también "femenino"), mantiene una relación afectiva duradera con Susan Silverman, doctora en psicología de Harvard, es aficionado al beisbol, hace ejercicio diariamente, y a lo largo de su vida se ha rodeado de una familia sustituta. Esto es, se ha integrado al american way of life de la década de los ochentas y como resultado ha perdido la posición marginal que caracterizaba a los detectives anteriores y que los ubicaba en una posición desde la cual podían hacer una crítica de su sociedad y proponer la ética alternativa que los determina.

${ }^{30}$ Ibid., p. 106. 
Las novelas de Spenser, todas narradas en primera persona, dejan patente que es un hombre culto que cita a Freud, a Shakespeare, a Gertrude Stein, a Emerson y Whitman. Además, su masculinidad debe explicitarse porque ya no es uno de los supuestos que el lector comparte con él. Aquellas nociones compartidas que formaban parte del sentido común y del discurso patriarcal que sustentaba la narración, ahora deben ser explicadas con aclaraciones como la siguiente: "You have to be autonomous. Dependent on yourself. Not influenced by things outside yourself" 31 , como señala la propia Susan:

It's where you lose me, this arcane male thing. It's like a set of rituals from a religion that no longer exists, the rules of a kingdom that disappeared before memory. It can't be questioned or explained, it simply is -like gravity or inertia [...] I realize it's a source of strength for you, but you pay a price for it too..$^{32}$

Compárese este comentario dicho con seriedad con un comentario semejante de Marlowe, quien se identifica y proyecta en la figura de un caballero que ve en un vitral cuando visita a un cliente:

[...] there was a broad stained-glass panel showing a knight in armor rescuing a lady who was tied to a tree and didn't have any clothes on but some very long and convenient hair. The knight had pushed the vizor of his helmet back to be sociable, and he was fiddling with the knots on the ropes that tied the lady to the tree and not getting anywhere. I stood there and thought that if I lived in the house, I would sooner or later have to climb up there and help him. He didn't seem to be really trying. ${ }^{33}$

En $A$ Catskill Eagle, novela en la que más parece un caballero que rescata a su dama de una fortaleza, Spenser piensa lo siguiente:

I thought of Susan. Of her intelligence, her strength, her deep interiority, and of the compassion of her face. I thought of "forever" and how we were forever. Forever. During my dark and silent progress forever was like a lighthouse and I thought of it again. Forever. It was

${ }^{31}$ Robert B. PARKER, Early Autumn, p. 113.

32 R. B. PARKer, Ceremony, p. 106.

${ }^{33}$ R. ChANDLER, The Big Sleep, p. 1. 
a fact. The fact. Susan and I were forever [...] The fact existed, unchangeable like eternity. ${ }^{34}$

Comparémoslo con lo dicho por Marlowe:

What did it matter where you lay once you were dead? In a dirty sump or in a marble tower on top of a high hill? You were dead, you were sleeping the big sleep, you were not bothered by things like that. Oil and water were the same as wind and air to you. You just sleep the big sleep, not caring about the nastiness of how you died or where you fell. ${ }^{35}$

La novela negra ha sufrido un proceso de sentimentalización, resultado de la repetición gratuita de la fórmula básica del género. Spenser mantiene lazos afectivos, tiene una vida privada y un hogar que funcionan como "the source of warmth"36 de su vida. Así, aunque las características del detective se han modificado conforme cambian los estereotipos de la época ( $A$ Catskill Eagle llega a parecerse a Rambo), su búsqueda es la misma y resulta inverosimil en su mundo. Además, el narrador repite una y otra vez las características que el detective supuestamente posee "naturalmente", se ve en la necesidad de explicar y justificar su comportamiento tan obsoleto en un mundo donde ya resulta casi absurdo porque "en el mundo de la normalidad se produce un momento en que éste carece de capacidad de entusiasmar a nadie", ${ }^{37}$ cosa que según Chandler no debería ser necesario: "[The detective] must be, to use a rather weathered phrase, a man of honour, by instinct, by inevitability, without thought of it, and certainly without saying it". ${ }^{38}$

Según Abraham Moles, el kitsch que caracteriza el american way of life de los ochentas y que Spenser ha asimilado se compone de los siguientes valores fundamentales: seguridad frente a las vicisitudes del mundo exterior, que se propone como un valor ideal; autoafirmación, ausencia de cuestionamiento de una forma de vida o de un sistema económico basados en la acumulación creadora y en la conservación de capital, de mercancías, de grandes tiendas o de objetos; sistema posesivo como valor esencial, donde el hombre es lo que aparenta, y aparenta por

34 R. B. PARKER, A Catskill Eagle, p. 294.

${ }^{35}$ R. CHANDLER, The Big Sleep, p. 215.

${ }^{36}$ R. B. PARKer, Ceremony, p. 107.

37 J. V. MARQUES, op.cit., p. 15.

${ }^{38}$ R. CHANDLER, "The Simple Art of Murder", en Pearls Are a Nuisance, p. 189. 
sus posesiones: el tamaño del departamento, la altura de los cielorrasos - la platería; Gemütlichkeit vinculada con el alma y el corazón, intimidad agradable y afectuosa, virtud de la comodidad, cosyness de la cultura anglosajona; ritual de un modo de vida. ${ }^{39}$ Es evidente que Spenser defiende el derecho que todo individuo tiene de acceder a estos valores fundamentales que garantizan el bienestar, pero lo hace desde adentro, como integrante de esa sociedad. Es ésta su diferencia fundamental con respecto a los detectives que lo preceden y es por esto mismo que se convierte en un detective inverosímil, porque la realidad literaria y el contrato narrativo que caracteriza al género no se han transformado.

No es sorprendente, entonces, que un detective como Spenser se convierta más en un padre, ahora que mujeres como Sara Paretsky y Sue Grafton crean a sus detectives V. I. Warshawski y Kinsey Millhone. La primera, divorciada, deja de ejercer como abogada, y Millhone, divorciada por segunda y última vez, deja el departamento de policía: " 'It's not that different from being a cop' I said. I'm not part of the bureaucracy, that's all. Don't wear a uniform or punch a time clock. I get paid more, but not as regularly' ". ${ }^{40}$ Las dos investigadoras son profesionales y eligieron su marginalidad conscientemente: "I' $m$ the only person I take orders from, not a hierarchy of officers, aldermen, and commissioners", 41 dice Warshawski. Ambas obtienen reconocimiento público como ciudadanas a cambio de su rechazo de las funciones tradicionales asignadas a las mujeres:

"But I'm a happy detective, Bobby, and I made a lousy housewife". That was true. My brief foray into marriage eight years ago ended in an acrimonious divorce after fourteen months: some men can only admire independent women at a distance. ${ }^{42}$

El "yo" ficcional de la novela policiaca narrada en primera persona es el "yo" unificado del egocentrismo masculino. Cuando las heroínas asumen este yo se convierten en la fuente, la garantía, las analistas y las comentaristas de la narración, así como en las productoras de su propia significación. Su constante autoanálisis irónico, que gira en torno a su yo narrado, se une a la expresión del yo que narra y afirmaría que para ellas el acto de narrar es un camino hacia la emancipación, puesto que es un

\footnotetext{
39 Abraham MOLES, El kitsch, p. 95.

${ }^{40}$ Sue Grafton, ' $E$ ' is for Evidence, p. 142.

41 Sara PARETSKy, Indemnity Only, p. 180.

42 Ibid., p. 30.
} 
proceso de concienciación. Tratan de reconciliar la oposición represiva femenino/masculino con la visión de una conciencia femenina integrada. Además, al representarse, las detectives destruyen la imagen del "yo" concebido desde fuera. Warshawski y Millhone conscientemente se dirigen a las mujeres lectoras, a quienes no postulan como el Otro amenazante sino como el "yo" no dividido, identificándose con una detective que dice: "I'm a woman, Mr. Thayer, and I can look out for myself. If I couldn't, I wouldn't be in this kind of business. If things get heavy, I'll figure out a way to handle them -or go down trying. That's my problem, not yours". ${ }^{43}$

Millhone nos dice algo similar: "As a lady in distress, I don't ordinarily call on men. I've been schooled in the notion that a woman, these days, saves herself, which I was willing to do if I could just figure out where to start". ${ }^{44}$

$\mathrm{Al}$ asumir el modelo masculino integrado lo desmitifican, volviéndo10 más accesible para una lectora que ya no se ve forzada a enfrentar discursos como los que siguen, que la excluyen como sujeto al tratarla como objeto:

"I was pleased -most men would be. I took her to dinner at L'Espalier. We had wine. We went to the Plaza Bar. We came home her..." Rojack made a shrugging hand-spread gesture; among us men of the world, it would be clear what happened next. ${ }^{45}$

I gave her the complete smile. The one where my eyes crinkle at the cor-ners and two deep dimples appear in my cheeks. Women often tore off their underwear and threw it at me when I gave them the complete smile. $^{46}$

Spenser mantiene una relación amorosa estable, pero ni Millhone ni Warshawski lo hacen a pesar del hecho de que tradicionalmente se cree que una mujer depende de sus relaciones y se reafirma en ellas:

About every six or eight months, I run into a man who astounds me sexually, but between escapades, I'm celibate, which I dont't think is

${ }^{43}$ Ibid., p. 9.

${ }^{44}$ S. GRAFTON, 'E' is for Evidence, p. 31.

${ }^{45}$ R. B. PARKER, Stardust, p. 76.

${ }^{46}$ R. B. PARKER, Playmates, p. 41. 
any big deal. After two unsuccessful marriages, I find myself keeping my guard up, along with my underpants. ${ }^{47}$

A diferencia de los detectives tradicionales, Spenser mantiene lazos afectivos, aunque jamás proporciona sus antecedentes particulares: es un hombre sin orígenes. Esto enfatiza el hecho de que Spenser es un selfmade man, independiente y libre de la responsabilidad que implica tener una familia, además de que reafirma la creencia de que los hombres son capaces de subsistir y de hacerse solos. En cambio, Warshawski y Millhone hablan de las mujeres que las criaron para que fueran como son: a Millhone la educó una "no-nonsense aunt who had done her best, who had loved me deeply, but with a matter-of-factness that had failed to nourish some part of me". ${ }^{48}$ Esta detective se representa así:

For the record, my name is Kinsey Millhone. I'm a private investigator, licensed by the State of California, (now) thirty-three years old, 118 pounds of female in a five-foot six-inch frame. My hair is dark, thick, and straight. I'd been accustomed to wearing it short, but I'd been letting it grow out just to see what it would look like. My usual practice is to crop my own mop every six weeks or so with a pair of nail scissors. This I do because I'm too cheap to pay twenty-eight bucks in a beauty salon. I have hazel eyes, a nose that's been busted twice, but still manages to function pretty well I think. If I were asked to rate my looks on a scale of one to ten, I wouldn't. I have to say, however, that I seldon wear makeup, so whatever I look like first thing in the morning at least remains consistent as the day wears on. ${ }^{49}$

Warshawski, por su lado, tenía una madre a la que describe así: "She was a fighter, and I got my scrappiness from her, not from my big, eventempered father". ${ }^{50}$ En las novelas de estas detectives se vislumbra una genealogia femenina. Esto es, y como dijo Virginia Woolf, "we think back through our mothers if we are women". ${ }^{51}$ Kinsey Millhone enfatiza la ficcionalidad del texto y de sí misma en los epílogos con los que concluye sus novelas. Para ella escribir es crearse, ya que carece de modelos. En Blood Shot, Warshawski hace referencia a Kinsey Millhone:

\footnotetext{
${ }^{47}$ S. GRAFTon, 'C' is for Corpse, p. 11.

48 Ibid., p. 56.

${ }^{49}$ S. GRAFTON, ' $G$ ' is for Gumshoe, p. 1.

${ }^{50} \mathrm{~S}$. PARETSKY, Indemnity Only, p. 76.

51 Virginia Woolf, A Room of One's Own, p. 72.
} 
"I've always been a little jealous of Kinsey Millhone's immaculate record-keeping; I didn't even have receipts for meals or gas" 52 y marca su diferencia con la tradición masculina: "Still, being a private investigator is not the romance of the loner knight that Marlowe and Spenser like to pretend - half the time you're doing some kind of tedious surveillance". 53

Tanto Paretsky como Grafton sacuden las convenciones del género al convertir a la mujer en el yo íntegro y no en el Otro: no son mujeres que buscan su continuidad en los otros, como las mujeres en las novelas narradas por hombres que recurren a sus feminine wiles para conseguir 1o que desean a través de los hombres. Las detectives, aunque $\tan$ solitarias como los detectives masculinos, son mujeres-para-si y no para-los-otros: "I do have friends, but I don't entertain", 54 dice Millhone, aunque cuenta con el apoyo de varias mujeres en su comunidad. En la última novela que se ha publicado, Warshawski reconoce que necesita el apoyo de otra mujer: "It's Lotty. I'm so scared - scared she's going to leave me the way my mother did. It didn't matter that I loved my mother, that I did what I could to look after her. She left me anyway. I don't think I can bear it if Lotty abandons me too".55

Las dos también se apegan a un código moral como los detectives masculinos, pero no les es exclusivo, ya que lo comparten con otras mujeres, aunque también mantienen su diferencia con ellas: "Does being a feminist mean you have to support everything your sisters do?"56 Además, ya no se toman su papel de heroínas tan en serio como los detectives masculinos:

In spite of the fact that I'm a social oaf, my aunt instilled a solid set of values, which prevailed in the end. By the time I graduated, I'd straightened up my act and now I'm a model citizen, give or take a civil code or two. At heart, I've always been a prissy little moralist. Private investigation is just my way of acting out. ${ }^{57}$

Spenser, por su parte, se representa así: "The world is full of people

52 S. PARETSKY, Blood Shot, p. 159.

53 S. PARETSKY, Burn Marks, p. 29.

54 S. GRAFTON, ' $C$ ' is for Corpse, p. 11.

55 S. PARETSKY, Guardian Angel, p. 416.

56 S. PARETSKY, Burn Marks, p. 334.

${ }^{57} \mathrm{~S}$. GRAFTON, ' $E$ ' is for Evidence, p. 110. 
I can't save. I get used to that. I got used to it on the cops. Any cop does. You have to or you go down the tube too". 58

Parecería evidente que no bastaría con que las heroínas sólo adopten características masculinas arbitrariamente porque la realidad literaria resultaría inverosímil. Esto puede mostrarse con un ejemplo sencillo. En Early Autumn Spenser enuncia uno de esos supuestos que pertenecen al discurso del sentido común y que es fundamental para la novela negra masculina: "A man's gotta do what a man's gotta do, boy". ${ }^{99}$ Esta oración tiene "the tautological force that masculinity itself has in our culture", ${ }^{60}$ y estabiliza la identidad masculina porque sugiere que el hombre es igual a sí mismo y a lo que hace. Pero la oración pierde sentido si sustituimos la palabra "hombre" por "mujer": "A woman's gotta do what a woman's gotta do". ¿Qué sucederia si sustituimos el masculino por el femenino en la definición que el mismo Chandler hace del detective ideal?

She is the heroine, she is everything. She must be a complete woman and a common woman and yet an unusual woman. She must be, to use a rather weathered phrase, a woman of honour, by instinct, by inevitability, without thought of it, and certainly without saying it. She must be the best woman in her world and a good enough woman for any world.

El "mundo" de la mujer es su hogar, una mujer "común" dificilmente puede considerarse una mujer de "honor". Las mujeres tenemos una posición distinta que la ocupada por los hombres frente a la experiencia femenil en una sociedad determinada. La realidad literaria de las novelas negras escritas por mujeres y con protagonistas femeninos es necesariamente diferente en tanto que remite a la experiencia femenina compartida por las mujeres. Así, se sustenta con valores, entendidos, preocupaciones y problemas que son de mujeres, como el aborto, la prostitución, la soledad, el hostigamiento sexual en el trabajo, la soledad de la vejez, la violencia doméstica, etcétera.

Cada lectora recrea una experiencia de lectura en términos de su identidad genérica. Siguiendo lo expuesto por Norman Holland y Leona Sherman, una lectora se enfrenta a un texto con un conjunto de expecta-

58 R. B. PARKer, Early Autumn, p. 58.

59 Ibid., p. 59.

${ }^{60}$ Tania MODLESK1, "Feminism and the Powerof Interpretation: Some Critical Readings", en Teresa de Lauretis, ed., Feminist Studies/Critical Studies, p. 134. 
tivas, de esperanzas y miedos: "We want the text to be the kind of world we know how to deal with". ${ }^{61}$ Esto es específicamente cierto en términos de la novela negra y de otros géneros como la novela rosa o los bestsellers norteamericanos dirigidos a un público femenil, donde las lectoras esperan tener una experiencia de lectura gratificante. El éxito de este tipo de literatura escapista es que da cabida a nuestras diferencias (o sea, a las diferencias que tendríamos con respecto a la protagonista) mientras se reafirma nuestra semejanza como mujeres. Al usar estrategias de adaptación como serían la defensa y la expectativa, como lectoras investimos el texto con conjuntos de deseos y de fantasías: "We match inner defenses and expectations to outer realities in order to project into them and then transform those fantasies into significance". ${ }^{62}$ Al dirigirse explícitamente a sujetos femeninos, estas novelas permiten que la experiencia de lectura no sea escindida, ya que las estrategias interpretativas generadas por el género literario son diferentes en tanto que son significativas para las preocupaciones, necesidades y experiencias de las mujeres como grupo.

Así, en vez de que una lectora tenga la necesidad de asumir la posición de lo que Judith Fetterley llamó un resisting reader frente a un texto androcéntrico, donde debe resistir una identificación plena con el protagonista para que su experiencia de lectura sea placentera, ahora es posible que la lectora se entregue a la lectura y se identifique cómodamente con "a hard-assed private eye waging a one-woman war against the bad guys everywhere". ${ }^{63}$

\section{Bibliografia}

BeLsEY, Catherine, "Constructing the Subject: deconstructing the text", en Judith Newton y Deborah RosenfELT, eds., Feminist Criticism and Social Change. Nueva York/ Londres, Methuen, 1985, pp. 45-64.

CAWELTI, John G., Adventure, Mystery and Romance. Chicago, University of Chicago Press, 1979.

${ }^{61}$ Norman N. Holland y Leona F. Sherman, "Gothic Possibilities", en Gender and Reading: Essays on Readers, Texts, and Contexts, p. 216.

${ }^{62}$ Ibid., p. 217.

${ }^{63}$ S. GRAFTON, ' $E$ ' is for Evidence, p. 70. 
CowARD, Rosalind, "The Story", en Female Desire. Londres, Paladin, 1987, pp.199-204.

Chandler, Raymond, "The Simple Art of Murder", en Pearls Are a Nuisance. Londres, Pan, 1980, pp. 173-190.

CHAndler, Raymond, Trouble is my Business. Nueva York, Vintage, 1988.

ChANDLER, Raymond, The Big Sleep. Nueva York, Ballantine, 1975.

Chandler, Raymond, Playback. Harmondsworth, Penguin, 1965.

ECo, Umberto, "El mito de Superman", en Apocalípticos e integrados. Trad. de Andrés Boglar. Barcelona, Lumen, 1985, pp. 249-297.

Grafton, Sue, ' $B$ ' is for Burglar. Nueva York, Bantam, 1988.

Grafton, Sue, 'C' is for Corpse. Nueva York, Bantam, 1988.

Grafton, Sue, 'E' is for Evidence. Nueva York, Bantam, 1989.

Grafton, Sue, 'G' is for Gumshoe. Nueva York, Fawcett Crest, 1990.

Holland, Norman N. y Leona F. Sherman, "Gothic Possibilities", en Elizabeth A. Flynn y Patrocinio P. Schweicrart, eds., Gender and Reading. Essays on Readers, Texts, and Contexts. Báltimor/Londres, The John Hopkins University Press, 1986, pp. 215-233.

JAMESON, Fredric, "Conclusion: The Dialectic of Utopia and Ideology", en The Political Unconscious. Londres, Methuen, 1986.

LaUreTIS, Teresa de, "The Technology of Gender", en Technologies of Gender. Essays on Theory, Film and Fiction. Bloomington, Indiana University Press, 1987, pp. 1-30.

LUKACS, Georg, "El espíritu burgués y 'L'art pour l'art'", en El alma y las formas. Teoria de la novela. Trad. de Manuel Sacristán. México, Grijalbo, 1985, pp.99-132. 
MARQUes, Josep-Vicent, "Masculino, femenino, neutro", en El Viejo Topo, extra, 10. 1976.

ModLESKI, Tania, "Feminism and the Power of Interpretation: Some Critical Readings", en Teresa de LaURETIS, ed., Feminist Studies/ Critical Studies. Bloomington, Indiana University Press, 1986, pp. 121-138.

MoI, Toril, Sexual/Textual Politics. Londres, Methuen, 1985.

NARCEJAC, Thomas, Una máquina de leer: la novela policiaca. Trad. de Jorge Ferreiro, México, FCE, 1986.

OwENs, Craig, "El discurso de los otros: las feministas y el posmodernismo", en Hal Forster, comp., El posmodernismo. Trad. de Jordi Fibla. Barcelona, Kairós, 1985, pp. 93-124.

Palmer, Jerry, Thrillers. La novela de misterio. México, FCE, 1983.

ParetSkY, Sara, Indemnity Only. Harmondsworth, Penguin, 1987.

PARetSKY, Sara, Blood Shot. Nueva York, Dell, 1988.

Paretsky, Sara, Burn Marks. Nueva York, Dell, 1990.

PARETSKY, Sara, Guardian Angel. Nueva York, Dell, 1992.

Parker, Robert B., Ceremony. Harm ondsworth, Penguin, 1987.

PARKER, Robert B., Early Autumn. Harmondsworth, Penguin, 1988.

PARKER, Robert B., A Catskill Eagle. Harmondsworth, Penguin, 1986.

PARKER, Robert B., Stardust. Nueva York, Berkley, 1991.

Showalter, Elaine, "Feminist Criticism in the Wilderness", en Elaine Showalter, ed., The New Feminist Criticism. Londres, Virago, 1986, pp. 243-270.

Woolf, Virginia, A Room of One's Own. Londres, Granada, 1982 